Article

\title{
New Asia Dust Storm Detection Method Based on the Thermal Infrared Spectral Signature
}

\author{
Hui Xu, Tianhai Cheng*, Xingfa Gu, Tao Yu, Yu Wu and Hao Chen \\ Institute of Remote Sensing and Digital Earth, Chinese Academy of Sciences, ChaoYang District, \\ Beijing 100101, China; E-Mails: xuhui2013@radi.ac.cn (H.X.); guxingfa@radi.ac.cn (X.G.); \\ yutao@radi.ac.cn (T.Y.); wuyu@radi.ac.cn (Y.W.); chenhao@radi.ac.cn (H.C.) \\ * Author to whom correspondence should be addressed; E-Mail: chength@radi.ac.cn or \\ cthy@irsa.ac.cn; Tel./Fax: +86-10-64839562.
}

Academic Editors: Dale A. Quattrochi and Prasad S. Thenkabail

Received: 13 September 2014 / Accepted: 5 December 2014 / Published: 23 December 2014

\begin{abstract}
As hyperspectral instruments can provide the detailed spectral information, a new spectral similarity method for detecting and differentiating dust from non-dust scenes using the Atmospheric Infrared Sounder (AIRS) observations has been developed. The detection is based on a pre-defined Dust Spectral Similarity Index (DSSI), which was calculated from the accumulated brightness temperature differences between selected 16 AIRS observation channels, in the thermal infrared region of $800-1250 \mathrm{~cm}^{-1}$. It has been demonstrated that DSSI can effectively separate the dust from non-dust by elevating dust signals. For underlying surface covered with dust, the DSSI tends to show values close to 1.0. However, the values of DSSI for clear sky surfaces or clouds (ice and water) are basically lower than those of dust, as their spectrums have significant differences with dust. To evaluate this new simple DSSI dust detection algorithm, several Asia dust events observed in northern China were analyzed, and the results agree favorably with those from the Moderate resolution Imaging Spectro radiometer (MODIS) and Cloud Aerosol LiDAR with Orthogonal Polarization (CALIOP) observations.
\end{abstract}

Keywords: Asia dust; thermal infrared signature; detection; AIRS 


\section{Introduction}

The occurrence of dust is a common phenomenon in arid and semi-arid regions of Northern China [1-3], particularly during springtime [4-8]. Airborne dusts originating from these areas are frequently transported over large regions in East Asia [9], producing severe air quality hazards along the transportation routes. Dust also plays an important role in the climate system [10,11], due to its complex direct and indirect effects on the state of atmosphere and the underling surface [12-19]. On the one hand, dust can directly reduce the surface insolation through its extinction of solar radiation, and heat the atmospheric layer by absorbing the solar radiation. On the other hand, it impacts the climate system indirectly by altering the cloud properties and precipitation. Accordingly, it is essential to accurately monitor the extent and intensity of dust, for the purpose of reducing or even avoiding the hazards caused by dust.

Since the advent of satellite technology, we have been able to routinely monitor dust through a variety of techniques [20-22]. As dust impacts earth outgoing longwave radiances in distinct way, monitoring dust with its infrared spectral signature has been extensively adopted among broadband infrared (IR) measurements [23-35], such as the widely used "IR split windows" (11 and $12 \mu \mathrm{m}$ channels) method $[7,22,24,26,28,30]$. However, due to the limited spectral resolution and wide channel spectral response, dust spectral radiances observed by broadband IR instruments show a strong dependence on the observational conditions [32], which often cause huge misidentification for dust scenes. For example, it has been reported $[7,34]$ that water cloud often displays a similar spectrum with airborne dust in the split window channels. Moreover, the used tri-spectral dust detection $(8.5,11$ and $12 \mu \mathrm{m}$ channels $)$ results also can be influenced by the presence of $\mathrm{SO}_{2}$, as $\mathrm{SO}_{2}$ has an absorption peek around $8.6 \mu \mathrm{m}$.

Recently, high spectral resolution satellite infrared measurements have become available, such as the Atmospheric Infrared Sounder (AIRS) and Infrared Atmospheric Sounding Interferometer (IASI). These sensors provide nearly 100 channels across the thermal infrared region $\left(800-1250 \mathrm{~cm}^{-1}\right)$, allowing us to monitor dust using a more accurate spectral information. Moreover, the design of narrow channel spectral response of hyperspectral instruments also provides us an opportunity to select more suitable dust observation channels (keep away from gases absorption peak). The possibility of utilizing hyperspectral instruments to retrieval dust from space has been discussed in the last decade. Sokolik [14] firstly carried out the research on the infrared hyperspectral radiative signature of mineral dust, concluding that the distinct ability of hyperspectral instruments for providing the detailed spectral information is very important in dust monitoring, since no other means of remote sensing from space are capable of providing such data. Gang Hong et al. [36] put their emphasis on the infrared signature of overlapping cirrus clouds and dust, finding that the spectral signature of the $800-1000 \mathrm{~cm}^{-1}$ region can be used to discriminate coexisting thin cirrus and dust scenes from those associated only with cirrus clouds or dust alone. By using the AIRS thermal infrared observations, Pierangelo et al. [37,38], DeSouza-Machado et al. [39] and Yao et al. [40] individually retrieved the dust altitude and infrared optical depth over different regions, and the results agree favorably with those from Ozone Monitoring Instrument (OMI), MODerate resolution Imaging Spectro-radiometer (MODIS), and Cloud Aerosol LiDAR with Orthogonal Polarization (CALIOP) observations. Gangle et al. [41] successfully developed a new volcanic ash detection method using their high spectral information provided by AIRS.

As accurate dust detection results are crucially important for the properties retrieval as well as evaluating its impact on regional weather and climate systems, thus, the main goal of this study is to 
exploit good discrimination of dust from non-dust scenes, by using the thermal infrared observations from AIRS hyperspectral measurement. The paper is organized as follows: a description of used datasets is given in Section 2; Section 3 outlines the physical basis and proposed new dust detection method; application and evaluation are performed in Section 4; finally, conclusions are presented in Section 5.

\section{Data}

\subsection{AIRS}

The Atmospheric Infrared Sounder (AIRS) on board NASA's Aqua satellite platform is a hyperspectral IR temperature and humidity sounder for numerical weather prediction and climate change studies [39]. It has 2378 infrared channels which can measure the earth outgoing radiation in the 3.7-15.4 $\mu \mathrm{m}$ region $(3.75-4.58,6.2-8.2,8.8-15.4 \mu \mathrm{m})$ with a spectral resolution of $\lambda / \Delta \lambda=1200$ and spatial resolution of $13.5 \mathrm{~km}$ (nadir field of view). The primary task of AIRS is to obtain the highly accurate temperature profiles within the atmosphere plus a variety of additional earth/atmosphere products (surface temperature, water vapor, and cloud properties). In this study, the daily Level 1B dataset which was downloaded from Goddard Earth Sciences Data and Information Services Center (GES DISC, http://disc.sci.gsfc.nasa.gov/AIRS/ data-holdings) is used.

\subsection{MODIS}

The MODerate resolution Imaging Spectro-radiometer (MODIS) shares the Aqua satellite with AIRS is a high spatial resolution instrument $(0.25 \mathrm{~km}, 0.5 \mathrm{~km}$, and $1 \mathrm{~km})$ that acquires data in 36 spectral bands ranging from 0.41 to $14.385 \mu \mathrm{m}$ [42]. Its Level 2 aerosol product [43] uses three different algorithms (Ocean, Dark Target, Deep Blue) to retrieve the ambient aerosol parameters over the oceans and the continents globally. The Deep Blue algorithm [21] is specially developed to retrieval aerosols, in particular, dust aerosol, over bright land surfaces. Therefore, the Level 1B RGB composite image (R: channel 1, G: channel 4, B: channel 3) and Level 2 deep blue aerosol optical depth (AOD) product downloaded from the ICARE Data Center (ICARE, http://www.icare.univ-lille1.fr/drupal/) are used in this paper, to evaluate and analyze the accuracy of the proposed dust detection result.

\subsection{CALIOP}

The Cloud Aerosol LiDAR with Orthogonal Polarization (CALIOP) instrument on board the CALIPSO platform, which provides the unique measurements of the global vertical distributions of clouds and aerosols $[39,40]$. It is a two wavelength LiDAR that transmits and receives backscattered light at laser wavelengths of $532 \mathrm{~nm}$ and $1064 \mathrm{~nm}$. The vertical resolutions are $30 \mathrm{~m}$ from the surface to $8 \mathrm{~km}$ altitude and $60 \mathrm{~m}$ above the $8 \mathrm{~km}$ altitude. The minimum horizontal resolution of a single profile is $330 \mathrm{~m}$, and a typical horizontal averaging interval is $5 \mathrm{~km}$ for aerosol and dust. CALIOP is a nadir only sensor which follows a similar ground track to AIRS (offset by $170 \mathrm{~km}$ from AIRS nadir). It is also a member of A-Train constellation, which means that measurements from AIRS and CALIOP can be easily compared to each other. In this paper, the Level 2 aerosol subtype data downloaded from the Atmospheric Science Data Center (ASDC, https://www-calipso.larc.nasa.gov/search) is used to support the analysis. 


\section{DSSI Dust Detection Method}

\subsection{Physical Basis}

Targets measured by satellite in thermal infrared region mainly include clear sky surface, airborne dust and cloud. To accurately differentiating dust from non-dust scenes, the spectrum differences between them are analyzed, by using the DIScrete Ordinates Radiative Transfer (DISORT) and Line By Line (LBL) models, as shown in Figure 1.
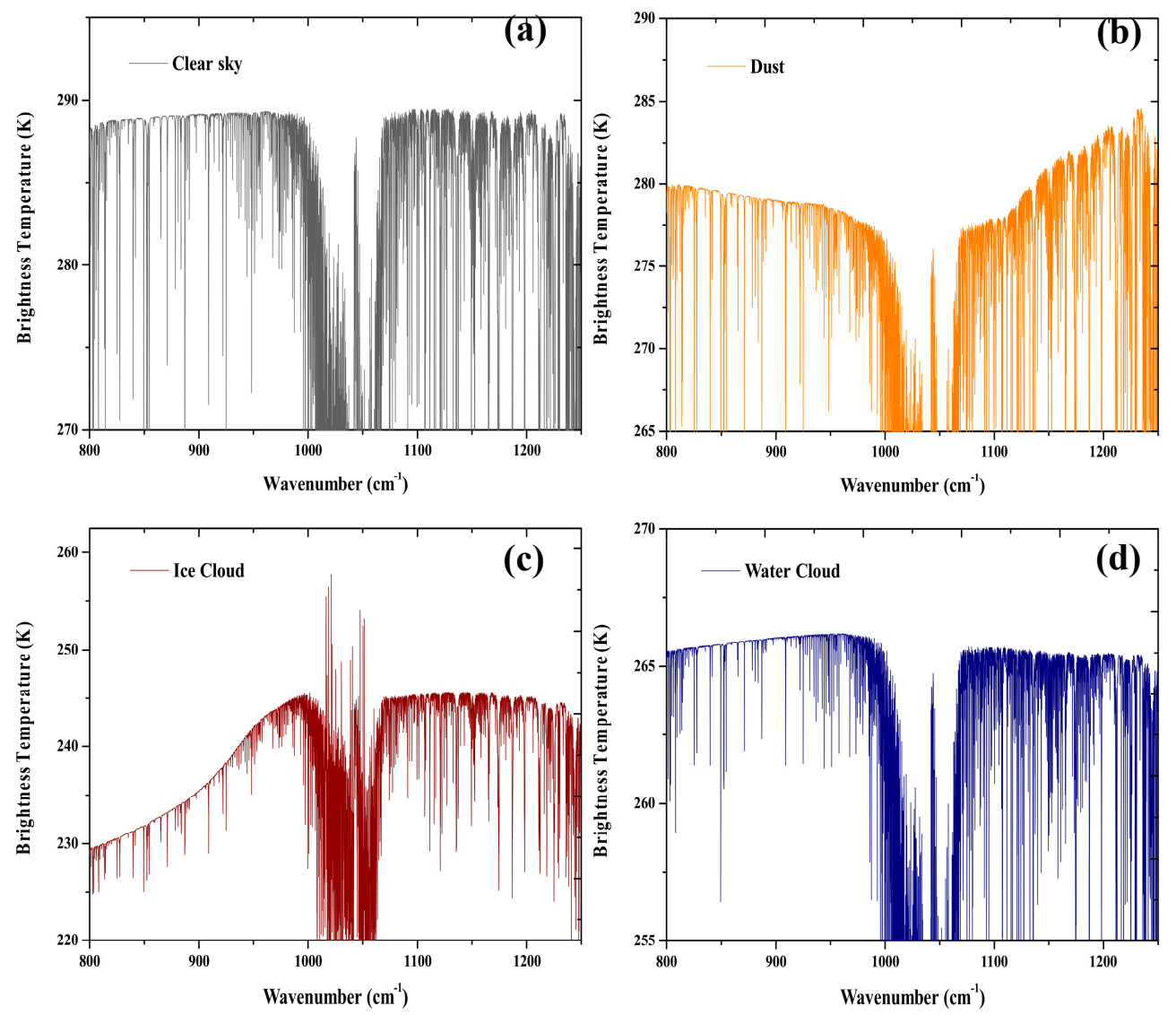

Figure 1. The simulated nadir-viewed spectral brightness temperatures under the conditions of (a) clear sky, (b) dust, (c) ice cloud and (d) water cloud.

For the microphysical description of dust, the size distribution is assumed as accumulated mode [44] specified in terms of lognormal function, and its standard deviation is 2.0. The refractive indices are taken from dust-like [45], due to its better depiction of Asian dust optical properties [46]. Microphysical models of water and ice cloud are derived from LibRadtran software dataset [47]. The size distribution of water cloud particle is assumed as gamma function, its standard deviation is 7.0, and the refractive indices of water cloud are assumed as liquid water. The optical properties of ice cloud $[48,49]$ are calculated from various ice crystal habits based on the in-situ horizontally averaged particle size distributions obtained from a variety of field campaigns in both mid-latitude and tropical locales. Specially, mixed-phase cloud is not considered in the current study as relationships of parameters within mixed-phase clouds are complicated and generally poorly correlated [50]. 
In the present radiative transfer simulation, a dust layer is assumed to be uniformly distributed in an altitude of $3 \mathrm{~km}$ with a thickness of $1 \mathrm{~km}$, as many researches have reported that dust is generally located around $1-5 \mathrm{~km}$ in altitude $[28,37]$. The optical depth of this dust layer at an infrared wavelength $(10 \mu \mathrm{m})$ is assumed to be 1.0, and the dust particle effective radius is set as $5.0 \mu \mathrm{m}$. The single layers of homogenous ice and water cloud with a thickness of $1 \mathrm{~km}$ are specified in an altitude of $10 \mathrm{~km}$ and $1 \mathrm{~km}$, respectively, as water cloud is often related to low level cloud and ice cloud usually locates at a higher altitude. The particle effective radius and infrared optical depth of ice and water cloud are individually considered as $15.0 \mu \mathrm{m}, 3.0$ (ice cloud layer) and $10.0 \mu \mathrm{m}, 10.0$ (water cloud layer). Moreover, the atmospheric molecular absorption is calculated from the LBL model based on the Middle Latitude Winter standard atmospheric profile [51], the surface temperature and emissivity are assumed as $290.0 \mathrm{~K}$ and 1.0, respectively. All the input parameters are listed in Table.1. Particularly, it is important to know that, if not specified, the default input parameters are set as values listed in Table 1 in the following forward simulation experiments, and while one or more parameters change, the others keep constant.

Table 1. The default input parameters for the forward simulation.

\begin{tabular}{cccc}
\hline Parameters & Dust & Ice Cloud & Water Cloud \\
\hline Optical Depth & 1.0 & 3.0 & 10.0 \\
Layer Height & $3.0 \mathrm{~km}$ & $10.0 \mathrm{~km}$ & $1.0 \mathrm{~km}$ \\
Particle Effective Radius & $5.0 \mu \mathrm{m}$ & $15.0 \mu \mathrm{m}$ & $10.0 \mu \mathrm{m}$ \\
Surface Temperature & & $290.0 \mathrm{~K}$ & \\
Surface Emissivity & \multicolumn{2}{c}{ Middle latitude winter atmospheric profile } \\
Atmospheric Profile & \multicolumn{2}{c}{ Nadir-viewed } \\
Observation Geometry & & 1.0 \\
\hline
\end{tabular}

It is interesting to see that the spectral segment of clear sky in the $800-1250 \mathrm{~cm}^{-1}$ region is essentially flat except for the ozone strong absorption region $\left(1000-1060 \mathrm{~cm}^{-1}\right)$, as shown in Figure 1a. However, the spectrum will change a lot in the presence of dust or cloud. More specifically, the simulated spectrum basically displays a "V" spectral shape which is resulted from a decreasing trend in the $800-1000 \mathrm{~cm}^{-1}$ region and an increasing trend in the $1060-1250 \mathrm{~cm}^{-1}$ region, in the presence of dust (Figure 1b). Unlike the case for dust, the spectrum of ice cloud in $800-1000 \mathrm{~cm}^{-1}$ region shows an obviously positive signature, and the variation of spectral brightness temperatures in $1060-1250 \mathrm{~cm}^{-1}$ region is generally flat, as evident from Figure 1c. The spectral shape of water cloud (Figure 1d) is very similar to that of clear sky, even though the brightness temperatures in the $800-1000 \mathrm{~cm}^{-1}$ region are overall higher than those in the $1060-1250 \mathrm{~cm}^{-1}$ region. In general, dust has a unique "V" spectral shape in the region of $800-1250 \mathrm{~cm}^{-1}$ through the comparison with clear sky surfaces and clouds. This distinct spectral shape should provide us a reliable way to monitor it from space.

\subsection{Channel Selection}

It is well known that water vapor and ozone are the main absorption gases in the thermal infrared region. Consequently, the channels selected for dust monitoring should have no or low sensitivity to them. Furthermore, as $\mathrm{SO}_{2}$ has an absorption peak near $8.6 \mu \mathrm{m}$, the selected dust observation channels should 
also avoid this particular region. Figure 2a shows the AIRS channel transmittances under the condition of clear sky. Specially, the channel transmittance is calculated through a high resolution monochromatic radiance integrated with the filter function over the bandwidth of AIRS observation channel, and the channel brightness temperature discussed in the following context is also calculated in this way.
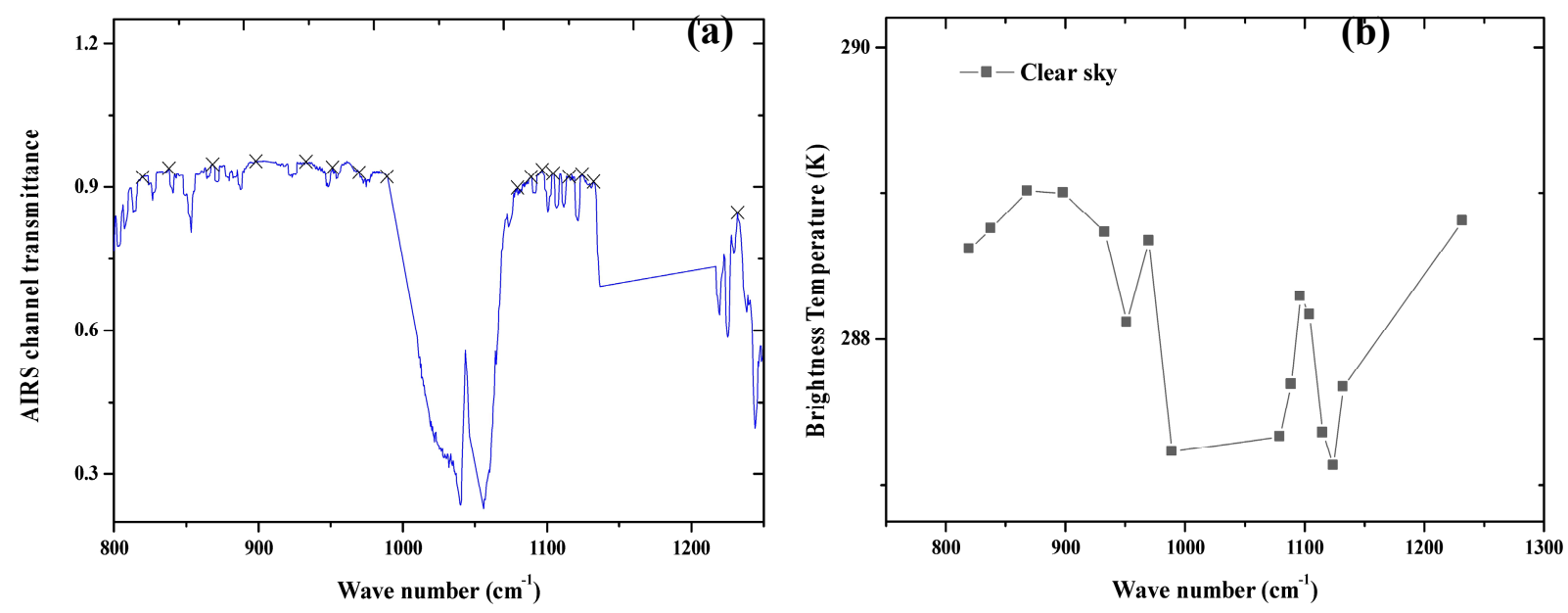

Figure 2. (a) The simulated nadir-viewed AIRS channel transmittances (blue line) under the condition of clear sky, and the selected dust observation channels (black cross) in the region of $800-1250 \mathrm{~cm}^{-1}$. (b) The simulated nadir-viewed spectral brightness temperatures of selected AIRS channels under the condition of clear sky.

From Figure $2 \mathrm{a}$, it is clear to see that there are many high transmittance channels existing in the region of 800-1250 $\mathrm{cm}^{-1}$ (e.g., channel transmittance greater than 0.9), which means that these channels are less affected by the gas absorption and can be well used to monitor the airborne dust. However, as the extinction abilities of dust in the adjacent channels are basically similar, consequently, the spectral shape of dust can be easily affected by non-dust factors if selected channels are very close to each other. Therefore, in order to accurately depict the unique "V" spectral shape of dust, 16 channels with different dust extinction abilities are selected, as the black cross marked in Figure 2a, and the detailed information of these channels are listed in Table 2. At last, the redundant channels with similar transmittance to the selected channels are removed, even though these channels also can be effectively used to monitor dust from space.

Table 2. AIRS selected channels ID, wavenumber, wavelength, and channel transmittance.

\begin{tabular}{cccc}
\hline AIRS Chanel (id) & Wavenumber $\left(\mathbf{c m}^{-1}\right)$ & Wavelength $(\boldsymbol{\mu m})$ & $\begin{array}{c}\text { Transmittance } \\
\text { (Middle Latitude Winter) }\end{array}$ \\
\hline 526 & 820.07 & 12.19 & 0.92 \\
572 & 837.93 & 11.93 & 0.94 \\
663 & 868.40 & 11.52 & 0.95 \\
752 & 897.90 & 11.14 & 0.95 \\
\hline
\end{tabular}


Table 2. Cont.

\begin{tabular}{cccc}
\hline AIRS Chanel (id) & Wavenumber $\left(\mathrm{cm}^{-1}\right)$ & Wavelength $(\mu \mathrm{m})$ & $\begin{array}{c}\text { Transmittance } \\
\text { (Middle Latitude Winter) }\end{array}$ \\
\hline 830 & 933.04 & 10.72 & 0.95 \\
879 & 951.66 & 10.51 & 0.94 \\
925 & 969.84 & 10.31 & 0.93 \\
973 & 988.67 & 10.11 & 0.92 \\
1152 & 1079.38 & 9.26 & 0.90 \\
1171 & 1088.88 & 9.18 & 0.92 \\
1186 & 1096.49 & 9.12 & 0.94 \\
1201 & 1104.20 & 9.06 & 0.93 \\
1222 & 1115.17 & 8.97 & 0.92 \\
1239 & 1124.20 & 8.90 & 0.93 \\
1254 & 1132.28 & 8.83 & 0.91 \\
1292 & 1231.85 & 8.12 & 0.85 \\
\hline
\end{tabular}

In Table 2, it is interesting to note that all the selected channels generally have a high transmittance except for the $1231.85 \mathrm{~cm}^{-1}$ channel. However, as it has less dust extinction compared with other channels, the relative changes in radiances observed in this channel can be used as a good indicator of dust. Figure $2 \mathrm{~b}$ shows the simulated nadir-viewed spectral brightness temperatures of the selected 16 dust channels under the condition of clear sky. As expected, the spectral shape of clear sky is very different with that of dust ("V").

\subsection{The Description of Dust Spectral Similarity Index (DSSI)}

The primary idea of the new proposed dust detection algorithm is to use its unique "V" spectral shape which has been discussed in the preceding context. Firstly, the observed 16 brightness temperatures are divided into two sub-datasets, with eight in the negative spectral slope region $(N-D S)$ and another eight in the positive spectral slope region $(P-D S)$, as shown in Equation (1).

$$
\begin{aligned}
& N-D S: B T_{820.07}^{526}, B T_{837.93}^{572}, B T_{868.40}^{663}, B T_{897.90}^{752}, B T_{933.04}^{830}, B T_{951.66}^{879}, B T_{896.84}^{925}, B T_{988.67}^{973} \\
& P-D S: B T_{1231.85}^{1292}, B T_{1132.28}^{1254}, B T_{1124.20}^{1239}, B T_{1115.17}^{1222}, B T_{1104.20}^{1201}, B T_{1096.49}^{1186}, B T_{1088.88}^{1171}, B T_{1079.38}^{1152}
\end{aligned}
$$

Parameter of $B T$ represents brightness temperature observed by selected channel, with superscript and subscript individually denoting the channel ID and the central wavelength. 
Secondly, a series of brightness temperature differences are separately calculated in the two sub-datasets, and the results are written as two triangular matrixes $(N(M)$ and $P(M))$, which are shown in Equation (2).

\begin{tabular}{|c|c|c|c|c|c|c|c|c|}
\hline \multirow{8}{*}{\multicolumn{2}{|c|}{$N(M)=$}} & $B T D_{526}^{572}$ & $B T D_{526}^{663}$ & $B T D_{526}^{752}$ & $B T D_{526}^{830}$ & $B T D_{526}^{879}$ & $B T D_{526}^{925}$ & $B T D_{526}^{973-}$ \\
\hline & & 0 & $B T D_{572}^{663}$ & $B T D_{572}^{752}$ & $B T D_{572}^{830}$ & $B T D_{572}^{879}$ & $B T D_{572}^{925}$ & $B T D_{572}^{973}$ \\
\hline & & 0 & 0 & $B T D_{663}^{752}$ & $B T D_{663}^{830}$ & $B T D_{663}^{879}$ & $B T D_{663}^{925}$ & $B T D_{663}^{973}$ \\
\hline & & 0 & 0 & 0 & $B T D_{752}^{830}$ & $B T D_{752}^{879}$ & $B T D_{752}^{925}$ & $B T D_{752}^{973}$ \\
\hline & & 0 & 0 & 0 & 0 & $B T D_{830}^{879}$ & $B T D_{830}^{925}$ & $B T D_{830}^{973}$ \\
\hline & & 0 & 0 & 0 & 0 & 0 & $B T D_{879}^{925}$ & $B T D_{879}^{973}$ \\
\hline & & 0 & 0 & 0 & 0 & 0 & 0 & $B T D_{925}^{973}$ \\
\hline & & 0 & 0 & 0 & 0 & 0 & 0 & 0 \\
\hline \multirow{8}{*}{$P(M)=$} & 0 & $B T D_{1292}^{1254}$ & $B T D_{1292}^{1239}$ & $B T D_{1292}^{1222}$ & $B T D_{1292}^{1201}$ & $B T D_{1292}^{1186}$ & $B T D_{1292}^{1171}$ & $B T D_{1292}^{1152}$ \\
\hline & 0 & 0 & $B T D_{1254}^{1239}$ & $B T D_{1254}^{1222}$ & $B T D_{1254}^{1221}$ & $B T D_{1254}^{1186}$ & $B T D_{1254}^{1171}$ & $B T D_{1254}^{1152}$ \\
\hline & 0 & 0 & 0 & $B T D_{1239}^{1222}$ & $B T D_{1239}^{1201}$ & $B T D_{1239}^{1186}$ & $B T D_{1239}^{1171}$ & $B T D_{1239}^{1152}$ \\
\hline & 0 & 0 & 0 & 0 & $B T D_{1222}^{1201}$ & $B T D_{1222}^{1186}$ & $B T D_{1222}^{1171}$ & $B T D_{1222}^{1152}$ \\
\hline & 0 & 0 & 0 & 0 & 0 & $B T D_{1201}^{1186}$ & $B T D_{1201}^{1171}$ & $B T D_{1201}^{1152}$ \\
\hline & 0 & 0 & 0 & 0 & 0 & 0 & $B T D_{1186}^{1171}$ & $B T D_{1186}^{1152}$ \\
\hline & 0 & 0 & 0 & 0 & 0 & 0 & 0 & $B T D_{1171}^{1152}$ \\
\hline & 0 & 0 & 0 & 0 & 0 & 0 & 0 & 0 \\
\hline
\end{tabular}

In Equation (2), BTD represents brightness temperature difference, with superscript and subscript together indicating which two channels are used for the calculation (e.g., $B T D_{526}^{572}$ means $B T_{820.07}^{526}$ minus $B T_{837.93}^{672}$ ).

At last, matrix elements with positive value are set as 1 , and the rest of them are set as 0 . Then, the new defined Dust Spectral Similarity Index (DSSI) is calculated through Equation (3) to imply the spectral similarity between dust ("V" spectral signature) and the target scene.

$$
D S S I=\frac{\left(\sum_{i=1}^{k} \sum_{j=i+1}^{k} N\left(M_{i, j}\right)\right)}{k(k-1) / 2} \times \frac{\left(\sum_{i=1}^{k} \sum_{j=i+1}^{k} P\left(M_{i, j}\right)\right.}{k(k-1) / 2}, k=8, M_{i, j}= \begin{cases}0, & \left(M_{i, j}<=0\right) \\ 1, & \left(M_{i, j}>0\right)\end{cases}
$$

In Equation (3), $N\left(M_{i, j}\right)$ and $P\left(M_{i, j}\right)$ represent matrix element, subscripts of $i$ and $j$ stand for the row and column number, respectively. $k(k-1) / 2$ is the total numbers of the calculated BTD in each matrix.

From Equation (1), it is interesting to note that, in the presence of dust, AIRS observed channel brightness temperatures in both the two sub-datasets would display a decreasing trend from left to right. That is to say, most of the elements in the upper triangular matrixes of Equation (2) should be positive when dust exists.

\subsection{The Sensitivity Analysis of DSSI}

The variation trend of DSSI under the conditions of dust and non-dust is discussed in this section, as shown in Figures 3-5.

Figure 3a to Figure 3e shows the dependence of the nadir-viewed infrared spectrum on the optical depth of dust. In addition to the preceding discussed "V" spectral signature, some other interesting features can be noticed. The spectral slopes in both the $800-1000 \mathrm{~cm}^{-1}$ and $1060-1250 \mathrm{~cm}^{-1}$ region are very sensitive to the optical depth of dust. Moreover, the overall variation patterns of the two spectral segments are nearly symmetric although the absolute value of the positive slope is slightly higher than 
that of the corresponding negative slope. Figure $3 \mathrm{f}$ shows the variation trend of DSSI under the condition of dust. As expected, DSSI has an obviously positive correlation with the optical depth of dust. In fact, with the increase of optical depth, the spectrum of clear sky surfaces turning more like the "V" spectrum under the impact of dust (as evident from Figure 3a to 3e), therefore, the value of DSSI will gradually increase to 1.0 along with the change of the spectrum.
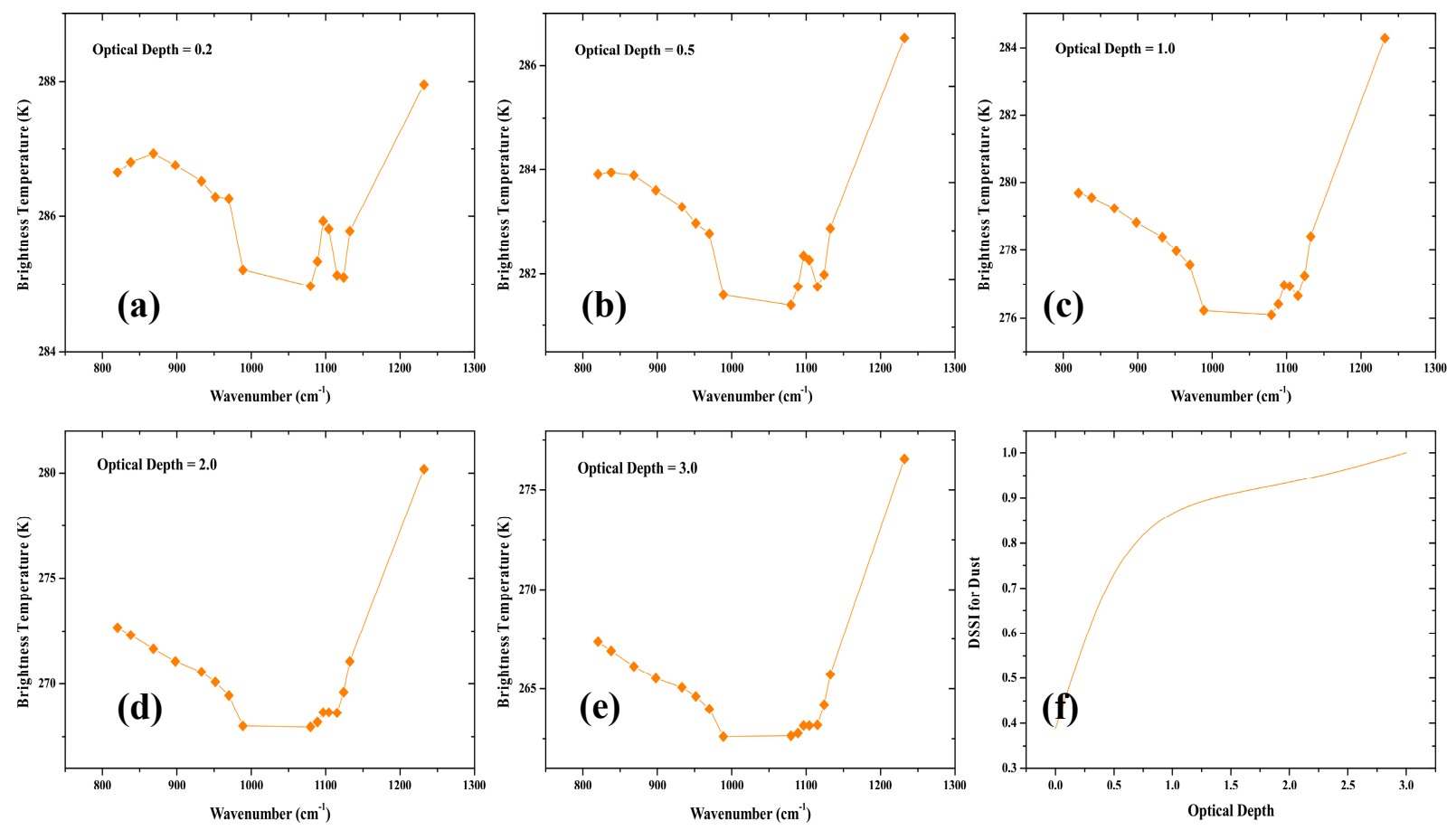

Figure 3. (a-e) The simulated nadir-viewed spectral brightness temperatures of selected AIRS channels for five different dust optical depths $(0.2,0.5,1.0,2.0$ and 3.0). (f) The variation trend of DSSI under the condition of dust.

Like the case for dust, the spectral shape of ice cloud becomes more pronounced as the optical depth increases (Figure 4a to Figure 4e), which featured with a positive slope in the region of $800-1000 \mathrm{~cm}^{-1}$. In addition, it has been found that, with the increase of the optical depth, ice cloud gradually reveals a reversed spectral shape with dust (positive spectral slope in $800-1000 \mathrm{~cm}^{-1}$ region and generally negative spectral slope in $1060-1250 \mathrm{~cm}^{-1}$ region). Therefore, in the presence of ice cloud, the dependency relationship between DSSI and optical depth should completely opposite to that of dust. As shown in Figure 4f, it is intuitive to see that DSSI indeed shows a strong negative correlation with the optical depth of ice cloud, in particular, clear sky surfaces covered by thick ice cloud basically show DSSI values close to zero.

The spectral variation of water cloud is also investigated, as shown from Figure 5a to Figure 5e. Not similar to both dust and ice cloud, the brightness temperatures of water cloud in $800-1000 \mathrm{~cm}^{-1}$ region gradually become higher than those in the $1060-1250 \mathrm{~cm}^{-1}$ region, and the DSSI of water cloud generally show a variation trend of first a decrease and then an increase, with the increase of optical depth. Additionally, it is important to note that the value of DSSI in the presence of ice and water cloud is obviously lower than that of dust, through the comparison of Figure 3f, Figure $4 \mathrm{f}$ and Figure $5 \mathrm{f}$. 

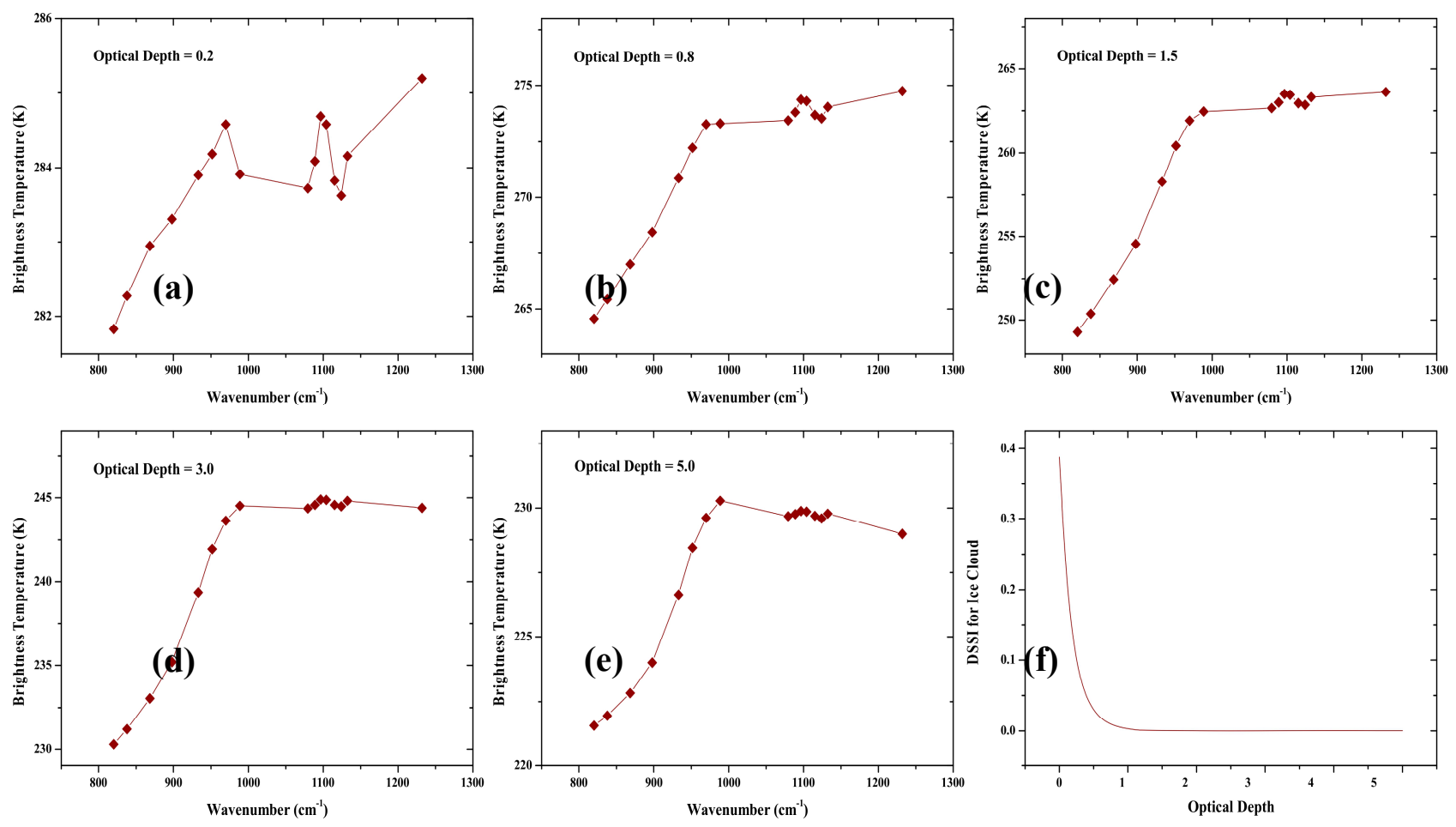

Figure 4. (a-e) The simulated nadir-viewed spectral brightness temperatures of selected AIRS channels for five different ice cloud optical depths $(0.2,0.8,1.5,3.0$ and 5.0). (f) The variation trend of DSSI under the condition of ice cloud.
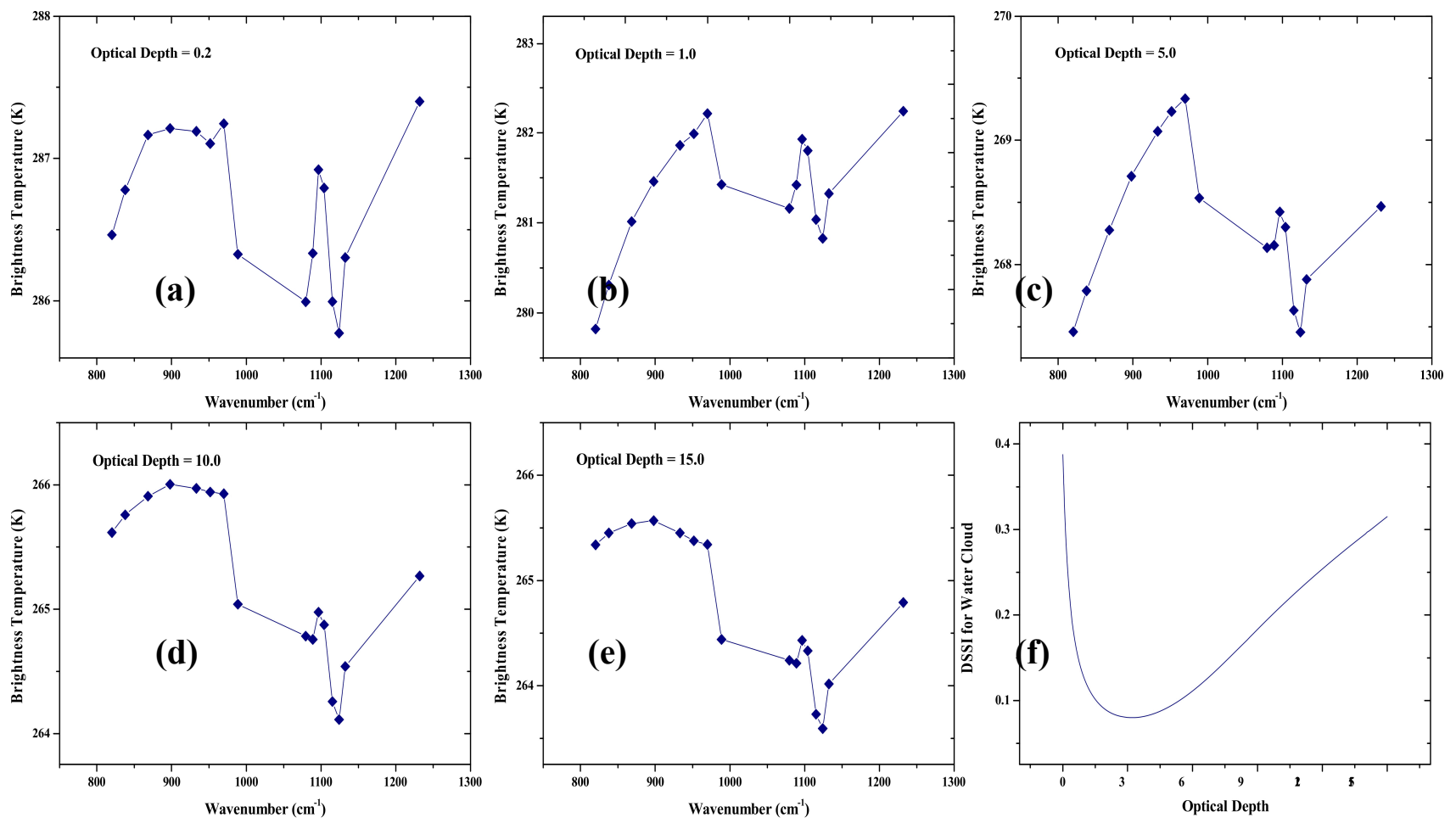

Figure 5. (a-e) The simulated nadir-viewed spectral brightness temperatures of selected AIRS channels for five different water cloud optical depths $(0.2,1.0,5.0,10.0$ and 15.0). (f) The variation trend of DSSI under the condition of water cloud. 
Satellite-observed radiance in thermal infrared region is mainly composed of two parts: the radiance emitted from dust (or cloud) layer and that transmitted from the underlying surface. The emitted radiances are highly determined by their layer temperatures (height) and optical properties (refractive index and size distribution), while the variation of underlying surfaces will affect largely the amount of the transmitted radiance from surface and also the satellite observed spectral shape. Therefore, to evaluate their effects on DSSI, the dependence of DSSI on optical depth was simulated for different layer heights, size distributions, and underlying surfaces, as shown from Figure 6 to Figure 9. However, it has to be noted that, owing to the lack of infrared refractive index in the literature, the effect of refractive index on DSSI is not discussed in current study, even though optical properties also show an obvious dependence on the particle composition.
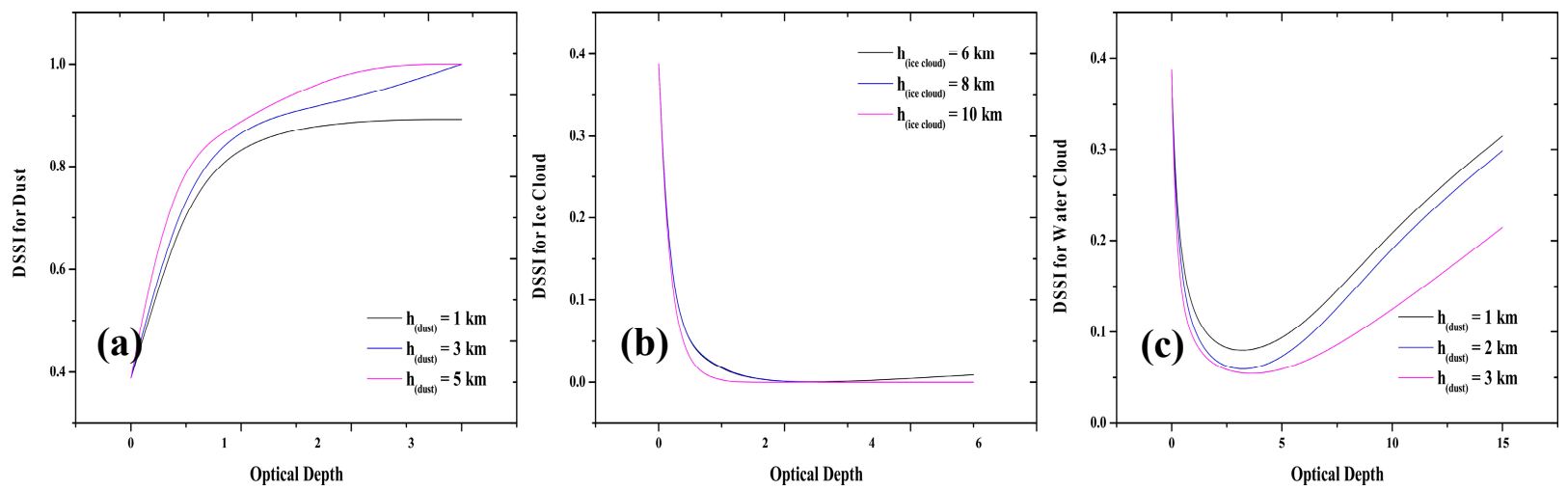

Figure 6. The effect of layer height $-\mathrm{h}$ on DSSI under the conditions of (a) dust (b) ice cloud (c) water cloud.

Figures 6 present an example of the simulated relationship between DSSI and optical depth with different dust and cloud layer heights. From Figure 6a, it is clear to see that DSSI slightly increases with the increase of dust layer height. This implies that high level dust can be more easily captured by the proposed DSSI method. However, for the cases of ice (Figure 6b) and water (Figure 6c) cloud, DSSI generally decreases with the increase of cloud layer height, even though the variation of ice cloud layer height actually has little influence on DSSI.
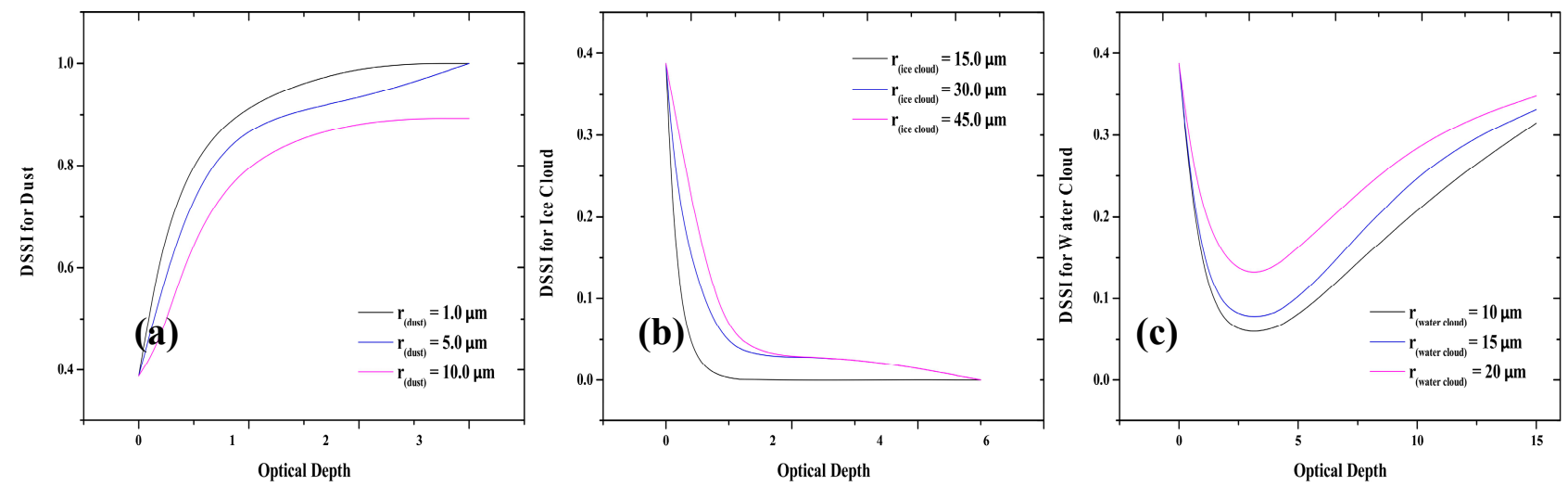

Figure 7. The effect of particle effective radius - $r$ on DSSI under the conditions of (a) dust (b) ice cloud (c) water cloud. 
Figure 7 shows the relationship between DSSI and optical depth with different particle effective radiuses. It is evident from Figure 7a that the DSSI of dust decreases with the increase of particle effective radius, which indicates that coarse dust particles can weaken its particular "V" spectral shape. In contrast, DSSI generally increases with the increase of particle effective radius under the conditions of ice and water cloud (Figure $7 \mathrm{~b}$ and $7 \mathrm{c}$ ). These suggest that finer particles of dust and cloud can be more easily distinguished between each other.

Figure 8 shows the effect of surface temperature on DSSI. In Figure $8 \mathrm{~b}$, it is easy to see that the DSSI for ice cloud is not sensitive to the surface temperature. However, when there is dust or water cloud, the variation of surface temperature has a great influence on DSSI, as evident from Figure 8a and 8c. Generally, the DSSI for dust decreases with the decrease of the underlying surface temperature. On the contrary, the DSSI for water cloud increases with the decrease of underlying surface temperature. This implies that underlying surface with low temperature would increase the difficulty in differentiating dust from water cloud.
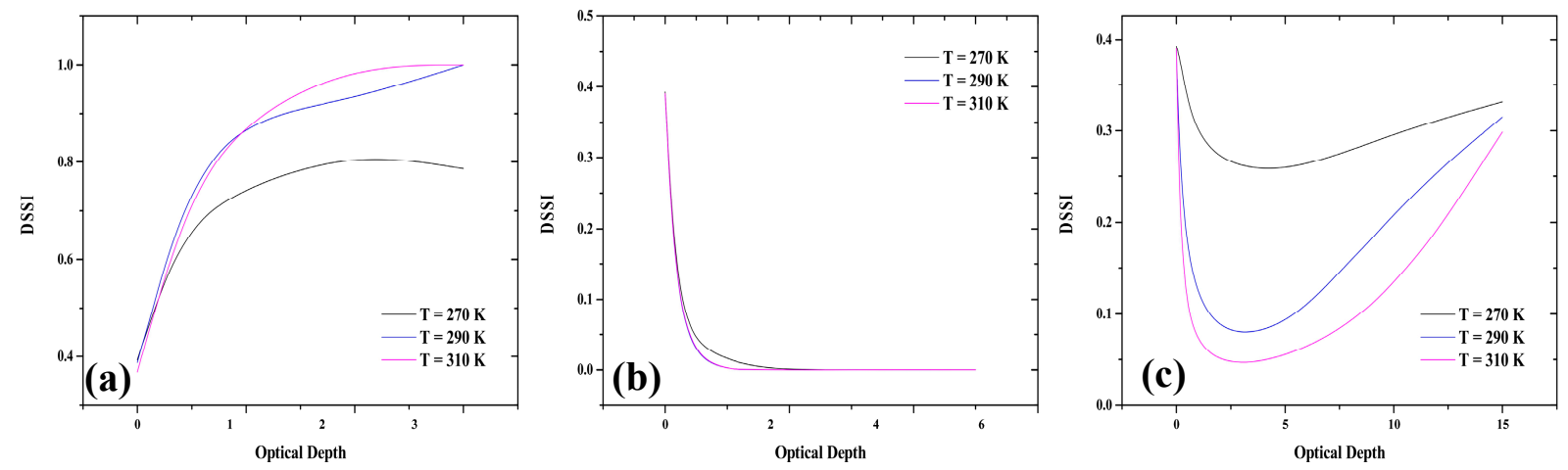

Figure 8. The effect of underlying surface temperature- $\mathrm{T}$ on DSSI under the conditions of (a) dust (b) ice cloud (c) water cloud.

Figure 9 demonstrates the relationship between DSSI and optical depth with different surface types. In the present simulation, the underling surfaces are assumed as ever green needle forest, grass land and desert to represent the dense vegetation, semiarid and arid areas, respectively. The emissivity data are obtained from the LibRadtran [47] surface property dataset, which was developed by NASA CERES (Clouds and the Earth's Radiant Energy System)/SARB (Surface and Atmospheric Radiation Budget) working group [52].
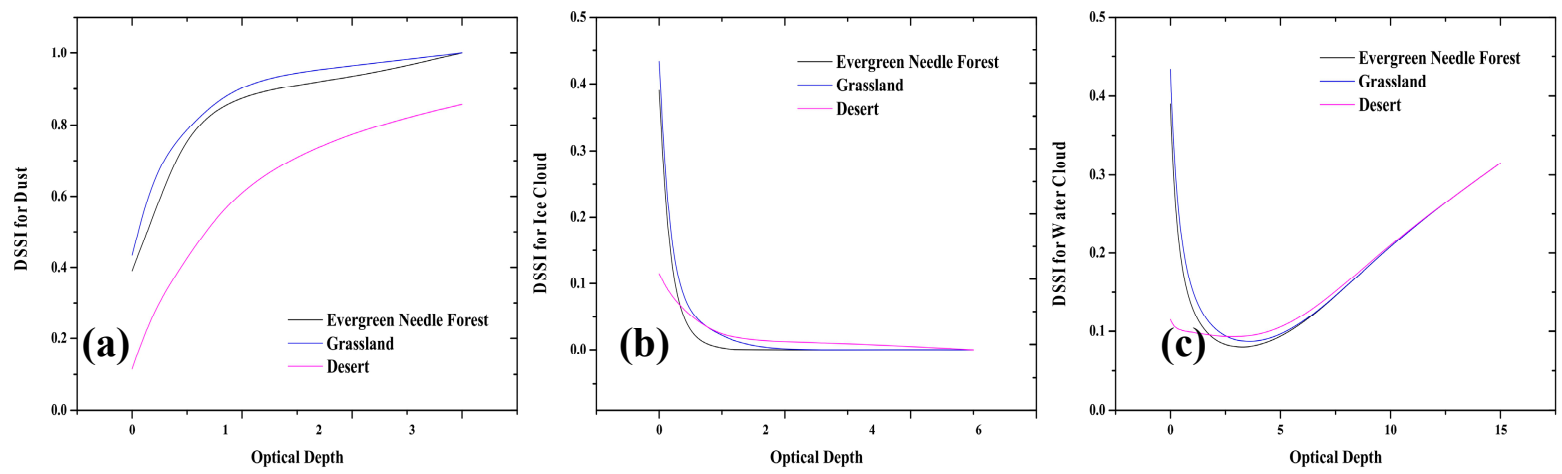

Figure 9. The effect of underlying surface type on DSSI under the conditions of (a) dust (b) ice cloud (c) water cloud. 
From Figure 9, it is intuitive to see that, the effect of surface emissivity on DSSI is not obvious over dense vegetation and semiarid regions. However, in the desert area, the value of DSSI is generally lower than that in the dense vegetation and semiarid areas. Another important point that should be noted is that dust can be effectively distinguished from clouds when the underlying surfaces are assumed as ever green needle forest (dense vegetation area) and grass land (semiarid and arid area). However, over the desert region, there are some overlaps between weak dust and thick water cloud in DSSI values, which may lead to a few misidentifications. Nevertheless, the proposed dust detection methods can be used in most instances, especially for dust storms.

In conclusion, dust eventually produces a DSSI near 1.0, on the contrary, cloud and clear sky surfaces generally show DSSI values much lower than those of dust. Thus, based on the proceeding forward simulation experiments, the threshold of $D S S I>0.6$ is used to discriminate dust from other scenes.

\section{Application}

For feasible analysis and robustness evaluation of this new simple dust detection algorithm, several strong dust activities that occurred over Northern China are analyzed in the following context.

\subsection{Case 1: 19 April 2008 Dust Event}

On 19 April 2008, a combination of dust and cloud hovered over most of the Taklimakan Desert. The RGB composite image captured by Aqua's MODIS instrument is shown in Figure 10a, brown line stand for the track path of CALIOP. As seen in this image, the dust storm originates from the eastern Taklimakan Desert, blowing massive loose sand and dust particles into the atmosphere and carrying them to the western areas. The aerosol optical depth derived from MODIS deep blue dataset shows the intensity distribution of this dust event (Figure 10b).

To evaluate the proceeding discussed dust and non-dust thermal infrared spectrums, the brightness temperatures of selected channels in cloudy (region A: marked by blue square in Figure 10a), dusty (region B: marked by red square in Figure 10a) and clear sky (region C: marked by orange square in Figure 10a) regions are extracted from the observations of AIRS, and the results are plotted in Figure 10c, 10d and 10e, respectively. Y-error bars plotted in these figures represent the standard error of mean (SEM) in corresponding sample regions. As expected, areas covered by dust indeed show a distinct "V" spectral shape. On the contrary, cloudy areas generally reveal a reversed spectrum with dust in this particular case. Moreover, the spectral signature of clear sky surfaces is absolutely different from that of dust and cloud. Another interesting point to be note is that, the spectrums that observed by AIRS highly correspond with the discussed forward simulation results, which not only implies the correctness of the preceding simulation experiments but also indicates the "V" spectral shape is the true spectral signature of Asian dust in the $800-1250 \mathrm{~cm}^{-1}$ region, providing us more confidence to monitor dust using this particular characteristic. Figure $10 \mathrm{f}$ displays the spatial distribution of DSSI calculated by the selected AIRS observation channels. Evidently, high values of DDSI are generally distributed over dusty areas, however, the values of $D D S I$ over non-dusty regions are basically lower than those of dusty areas. This phenomenon confirms that DDSI can elevate the signal of dust in the thermal infrared observations. 

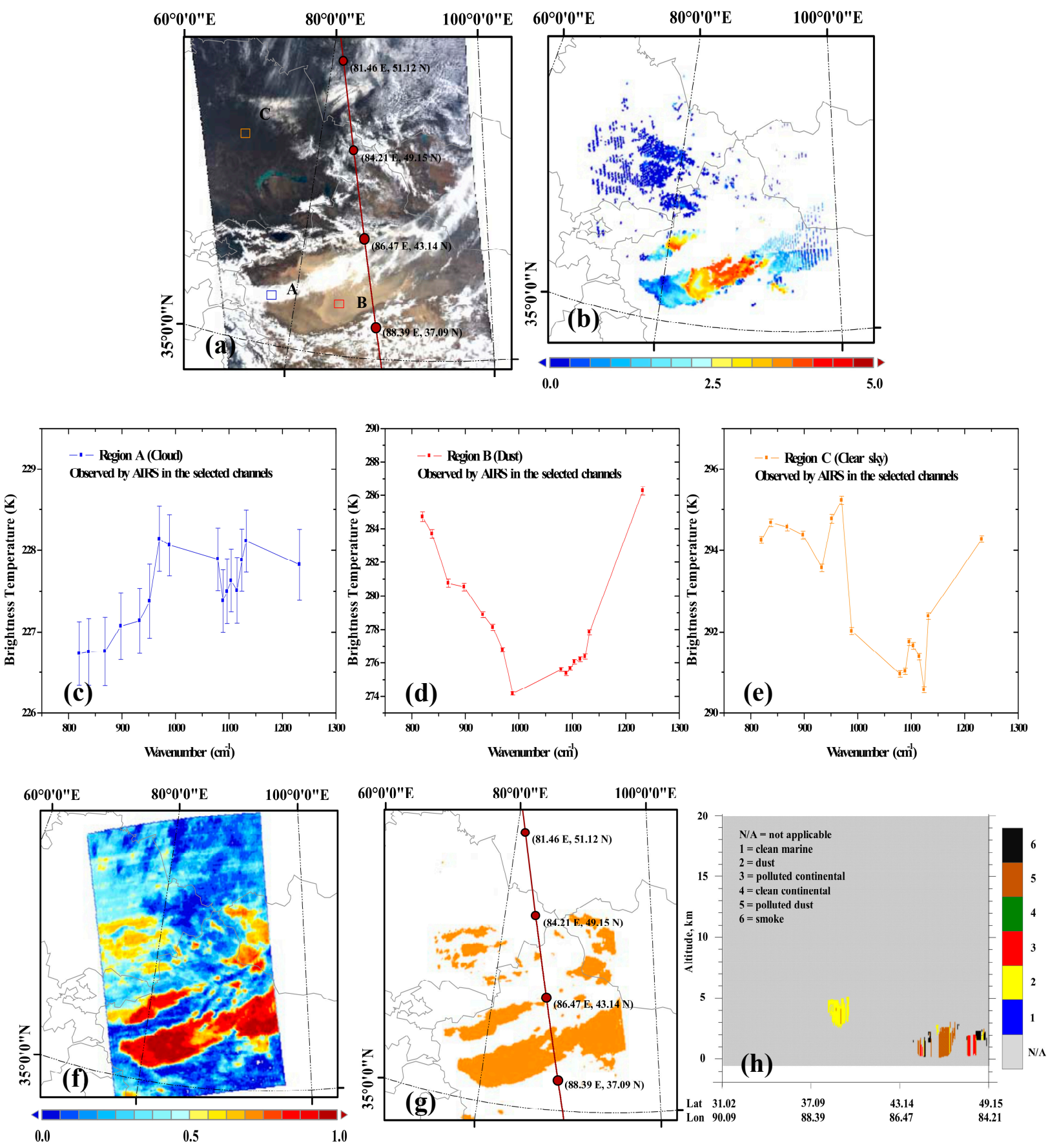

Figure 10. 19 April, 2008 (a) MODIS RGB composite image. (b) MODIS deep blue aerosol optical depth. (c) AIRS observations in cloudy region. (d) AIRS observations in dusty region. (e) AIRS observations in clear sky region. (f) DSSI. (g) Dust detection results based on DSSI. (h) CALIOP aerosol subtype.

Based on the proposed DSSI detection method, areas covered by dust are identified, as shown in Figure $10 \mathrm{~g}$. It is obvious to see that light brownish dust plumes have been clearly identified, and the distribution pattern of DSSI detection results seems to correlate well with that from MODIS aerosol optical depth. Figure 10h shows the retrieved aerosol subtype results from CALIOP backscatter data, yellow signals represent the dust. Compared with Figure $10 \mathrm{~g}$, the dust identification results from CALIOP also agree well with those from the proposed DSSI method along the track, and both of them 
indicate that massive airborne dust distributed between $37.13^{\circ}$ and $46.46^{\circ}$ in latitude. These demonstrate that DSSI is helpful in differentiating dust from non-dust scenes.

\subsection{Case 2: 11 May 2011 Dust Event}

On 11 May 2011, a springtime dust storm occurred over Northern China. The RGB composite image that captured by Aqua's MODIS instrument is shown in Figure 11a. In this image, it is clear to see that dust appears as a beige blur over the landscape and coexisted with cloud form a giant swirl. As the MODIS deep blue aerosol optical depth shows (Figure 11b), strong dusty areas are mainly located at the border of Inner Mongolia.

Figure 11c, 11d and 11e depicted the spectral brightness temperatures in cloudy (region A: marked by blue square in Figure 11a), dusty (region B: marked by red square in Figure 11a) and clear sky (region $\mathrm{C}$ : marked by orange square in Figure 11a) regions which were measured by selected channels of AIRS. The thermal infrared spectral signature of this dusty area also reveals a similar spectral shape of "V" with the forward simulation results that are plotted in Figure 3. Over the cloudy region, the observed spectrum in the $800-1000 \mathrm{~cm}^{-1}$ region is basically featured with a positive slope, which indicates that these areas are probably covered by the ice cloud. The observed spectral shape of clear sky surfaces also agrees well with that from the proceeding forward simulation experiment (depicted in Figure $2 b$ ). Figure 11f shows the spatial distribution of calculated DSSI. From Figure 11f, it may be deduced that the information about dust (red value regions) was obviously enhanced by the proposed method, and its $D S S I$ values are overall higher than those from clear sky and cloudy regions. The DSSI dust identification results are given in Figure 11g. Through the comparison with MODIS composite image, it is easy to see that dusty areas were accurately extracted from cloudy and clear sky regions. Furthermore, the distribution pattern of retrieved MODIS deep blue aerosol optical depth is also highly consistent with that of DSSI dust detection results.

The most commonly used broadband-based dust detection technique is often referred to as the "IR split windows" technique, which uses the negative value of brightness temperature difference between 11 and $12 \mu \mathrm{m}$ to infer the dust contaminated scenes. Figure $11 \mathrm{~h}$ shows the "IR split windows" dust detection results based on MODIS channel 31 and 32 observations. For the sake of spatial resolution consistency, MODIS data were resampled to the same spatial resolution of AIRS using Inverse Distance Weighting (IWD) interpolation method before the "IR split windows" technique was applied. Through the comparison of Figure 11a, 11b, 11g and 11h, we observe that the "IR split windows" algorithm actually identified some of the clouds and clear sky surfaces (such as the purple circles depicted in these figures, pink square represents the intersection coverage part of MODIS and AIRS) as dust plumes, while some of these ambiguous areas can be easily distinguished between each other by using the proposed DSSI method based on the AIRS instruments. This finding implies that hyperspectral instruments have the potential ability to provide better discrimination of dust from non-dust scenes and hence may help to overcome some of the problems using current broadband IR measurements. 

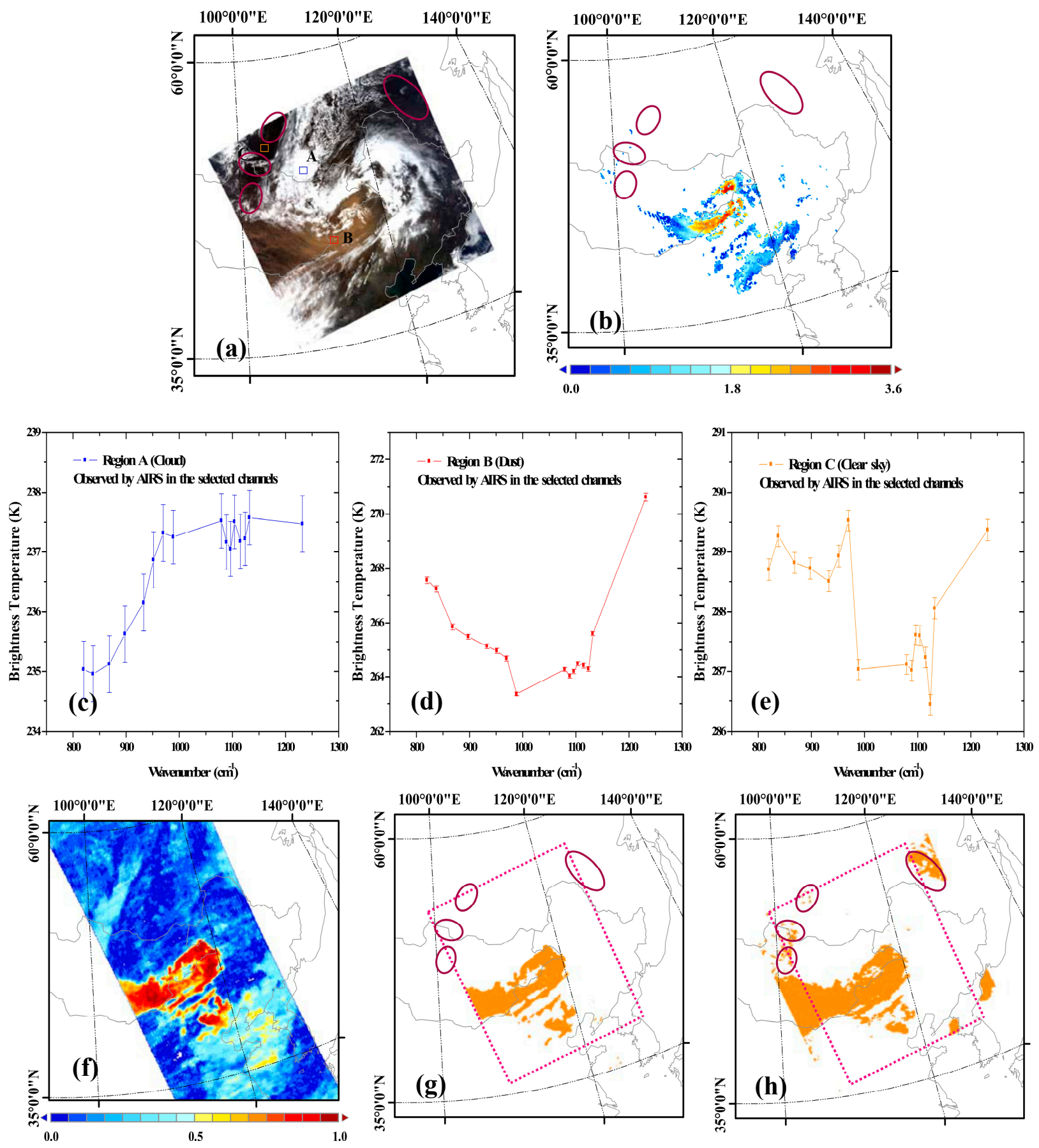

Figure 11. 11 May, 2011 (a) MODIS RGB composite image. (b) MODIS deep blue aerosol optical depth. (c) AIRS observations in cloudy region. (d) AIRS observations in dusty region. (e) AIRS observations in clear sky region. (f) DSSI. (g) Dust detection results based on DSSI.

(h) Dust detection results based on "IR split windows".

\subsection{Several Other Dust Cases}

To make a further evaluation and validation on the accuracy of the proposed DSSI dust detection algorithm, several other dust events that occurred in the arid and semi-arid areas of northern China are applied in this section.

Figure 12 shows the selected three Asia dust storms. The images from left to right are MODIS RGB composite image, retrieved MODIS deep blue aerosol optical depth results and the proposed DSSI dust 
detection results. The occurrence dates are 25 February, 2005 (Figure 12a), 1 March, 2008 (Figure 12b) and 22 April, 2012 (Figure 12c), respectively. It is interesting to note that, most of the brownish dusty regions can be accurately detected through the proposed DSSI algorithm, and the DSSI dust detection results correlate favorably with the retrieved MODIS aerosol optical depth in spatial distribution.

In summary, the proposed new dust detection algorithm works very well for many dust events evaluated in this work, which confirms that this method is indeed useful and reliable for monitoring the outbreaks and dispersion of Asian dust.
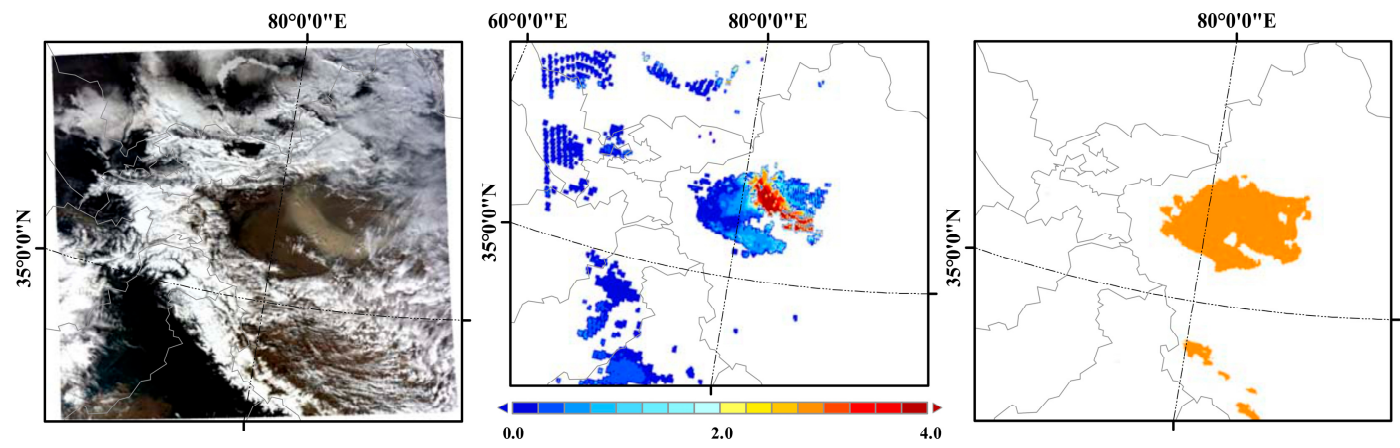

(a) 25 February 2005
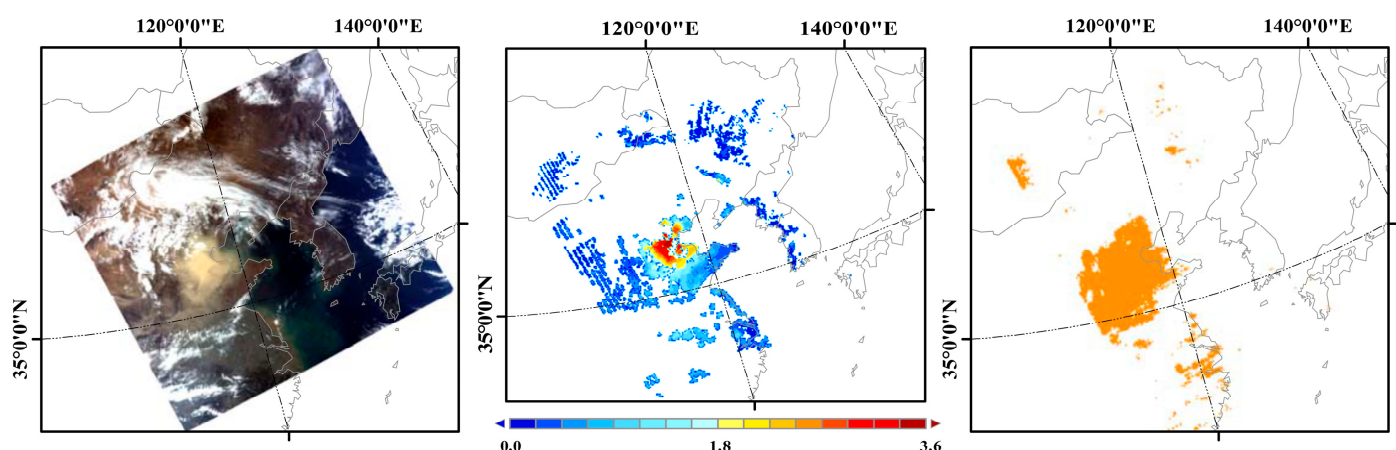

(b) 1 March 2008
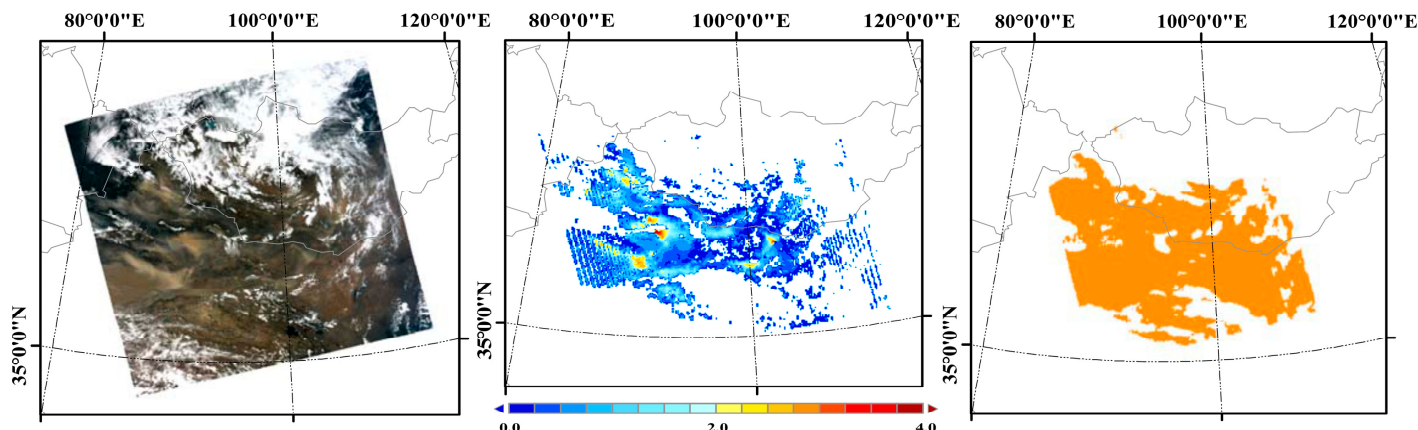

(c) 22 April 222012

Figure 12. Asia dust events occurred over northern China (a) 25 February 2005; (b) 1 March 2008; (c) 22 April 2012. Images from left to right are MODIS RGB composite image, MODIS deep blue aerosol optical depth and DSSI dust detection result, respectively.

\section{Conclusions}

A new DSSI algorithm was developed to detect Asian dust using the infrared hyperspectral instrument. This method relies on the spectrum differences between dust and non-dust scenes in the thermal infrared region, which could provide us a new insight on the detection of dust. To evaluate the feasibility and 
robustness of the proposed DSSI dust detection method, a series of dust events observed by AIRS over northern China are conducted. High spatial distribution consistency between the DSSI dust detection results and other A-Train satellite observations (MODIS and CALIOP) were discovered, which suggests that the DSSI algorithm can effectively differentiating dust from cloud and clear sky surfaces. Furthermore, many successfully applied dust cases also reveal its potential ability to conduct operational dust monitoring. Particularly, the work reported here could be easily adapted for other infrared hyperspectral sensor applications, such as IASI.

Although dust could be accurately extracted with the proposed method, more efforts and improvements still need to be pursued in the near future. Given that the spectrum of dust is highly dependent on the dust sources, the dust composition and optical properties over different dust active regions (e.g., the Sahara region of Africa, southwest desert of Australia) will be considered in subsequent researches, to extend the applicability of the proposed algorithm. Presently, dust detection results could be affected by the variation of underlying surfaces. To remove the influence of underlying surface, a dynamic reference background map of DSSI will be established in our next work. Also, quantitative assessment for dust detection results (such as, false detection and agreement) will be performed in the near future based on long time series AIRS datasets.

\section{Acknowledgments}

This study was funded by the National Natural Science Foundation of China (No. 41401422), Major State Basic Research Development Program of China (No. 2010CB950800) and National "Twelfth Five-Year" Plan for Science \& Technology Support (No. Y1K00200KJ). Additionally, the authors gratefully acknowledge the GES-DISC, ICARE as well as ASDC for the provision of used scientific remote sensing data. At last, the authors would like to specifically thank three anonymous reviewers for their constructive and valuable comments, which led to a significantly improved paper.

\section{Author Contributions}

All authors assisted in the analyzing and editing of the paper. Hui $\mathrm{Xu}$ is the main author who processed the data, developed the methodology, analyzed the results and wrote the manuscript.

\section{Conflicts of Interest}

The authors declare no conflict of interest.

\section{References}

1. Zhang, X.; Arimoto, R.; An, Z.S. Dust emission from Chinese desert sources linked to variations in atmospheric circulation. J. Geophys. Res. 1997, 102, 28041-28047.

2. Xuan, J; Liu, G.L.; Du, K. Dust emission inventory in Northern China. Atmos. Environ. 2000, 34, 4565-4570.

3. Natsagdorj, L.; Jugder, D.; Chung, Y. Analysis of dust storms observed in Mongolia during 1937-1999. Atmos. Environ. 2003, 37, 1401-1411. 
4. Shao, Y.; Dong, C. A review on East Asian dust storm climate, modeling and monitoring. Glob. Planet. Change 2006, 52, 1-22.

5. Xuan, J.; Sokolik, I. Characterization of sources and emission rates of mineral dust in Northern China. Atmos. Environ. 2002, 36, 4863-4876.

6. Liu, X.; Yin, Z.; Zhang, X.; Yang, X. Analyses of the spring dust storm frequency of Northern China in relation to antecedent and concurrent wind, precipitation, vegetation, and soil moisture conditions. J. Geophys. Res. 2004, 109, doi:10.1029/2004JD004615.

7. Zhang, P.; Lu, N.M.; Hu, X.Q.; Dong, C.H. Identification and physical retrieval of dust storm using three MODIS thermal IR channels. Glob. Planet. Change 2006, 52, 197-206.

8. Wang, X.; Huang, J.; Ji, M.; Higuchi, K. Variability of East Asia dust events and their long-term trend. Atmos. Environ. 2007, 42, 3156-3165.

9. Kim, J. Transport routes and source regions of Asian dust observed in Korea during the past 40 years (1965-2004). Atmos. Environ. 2008, 42, 4778-4789.

10. Haywood, J.; Oliviler, B. Estimates of the direct and indirect radiative forcing due to tropospheric aerosol: A Review. Rev. Geophys. 2000, 38, 513-543.

11. Higurashi, A; Nakajima, T. Detection of aerosol types over the East China Sea near Japan from four-channel satellite data. Geophys. Res. Lett. 2002, 29, 171-174.

12. Levin, Z.; Ganor, E.; Gladstein, V. The effects of desert particles coated with sulfate on rain formation in the Eastern Mediterranean. J. Appl. Meteorol. 1996, 35, 1511-1523.

13. Miller, R.L.; Tegen, I. Climate response to soil dust aerosols. J. Climate 1998, 11, 3247-3267.

14. Sokolik, I. The spectral radiative signature of wind-blown mineral dust: Implications for remote sensing in the thermal IR region. Geophys. Res. Lett. 2002, 29, doi:10.1029/2002GL015910.

15. Gu, Y.; William, I.; Gregg, J. Retrieval of mass and sizes of particles in sandstorms using two MODIS IR bands: A case study of April 7, 2001 sandstorm in China. Geophys. Res. Lett. 2003, 30, doi:10.1029/2003GL017405.

16. Huang, J.; Lin, B.; Minnis, P.; Wang, T.H.; Wang, X.; Hu, Y.X.; Yi, Y.H.; Ayers, J.K. Satellite-based assessment of possible dust aerosols semi-direct effect on cloud water path over East Asia. Geophys. Res. Lett. 2006, 33, doi:10.1029/2006GL026561.

17. Huang, J.; Wang, Y.; Wang, T.; Yi, Y.H. Dusty cloud radiative forcing derived from satellite data for middle latitude regions of East Asia. Process Nat. Sci. 2006, 16, 1084-1089.

18. Huang, J.; Minnis, B.; Lin, T.; Wang, Y.; Yi, Y.; Hu, S.; Sun-Mack; Ayers, K. Possible influences of Asian dust aerosols on cloud properties and radiative forcing observed from MODIS and CERES. Geophys. Res. Lett. 2006, 33, doi:10.1029/2005GL024724.

19. Zhu, A.; Ramanathan, V.; Li, F.; Kim, D. Dust plumes over the Pacific, Indian, and Atlantic oceans: Climatology and radiative impact. J. Geophys. Res. 2007, 112, doi:10.1029/2007JD008427.

20. Torres, O.; Bhartia, P.K.; Herman, J.R.; Ahmad, Z.; Gleason, J. Derivation of aerosol properties from a satellite measurement of backscattered ultraviolet radiation: Theoretical basis. J. Geophys. Res. 1998, 103, 17099-17110.

21. Hsu, N.C.; Si-Chee, T; King, M.D.; Herman, J.R. Aerosol properties over bright-reflecting source regions. IEEE Geosci. Remote Sens. 2004, 42, 557-569.

22. Wen, S.; Rose, W.I. Retrieval of sizes and total masses of particles in volcanic clouds using AVHRR bands 4 and 5. J. Geophys. Res. 1994, 99, 5421-5431. 
23. Ackerman, S. Remote sensing aerosols using satellite infrared observations. J. Geophys. Res. 1997, 102, 17069-17079.

24. Ackerman, S.A.; Strabala, K.I.; Menzel, W.P.; Frey, R.; Moeller, C.; Gumley, L.; Baum, B.A.; Seeman, S.W.; Zhang, H. Discriminating Clear-Sky from Cloud with MODIS Algorithm Theoretical Basis Document (MOD35). Available online: http://modis-atmos.gsfc.nasa.gov/_docs/ atbd_mod06_old.pdf (accessed on 13 September 2014).

25. Legrand, M.; Plana-Fattori, A.; N'doumé, C. Satellite detection of dust using the IR imagery of Meteosat: 1. Infrared difference dust index. J. Geophys. Res. 2001, 106, 18251-18274.

26. Miller, S.D. A consolidated technique for enhancing desert dust storms with MODIS. Geophys. Res. Lett. 2003, 30, doi:10.1029/2003GL018279.

27. Gary, P.; Bernadette, H.; Donald, W. Improved detection of airborne volcanic ash using multispectral infrared satellite data. J. Geophys. Res. 2003, 108, doi:10.1029/2002JD002802.

28. Roskovensky, J.K.; Liou, K.N. Differentiating airborne dust from cirrus clouds using MODIS data. Geophys. Res. Lett. 2005, 32, doi:10.1029/2005GL022798.

29. Brindley, H.E.; Russell, J.E. Improving GERB scene identification using SEVIRI: Infrared dust detection strategy. Remote Sens. Environ. 2006, 104, 426-446.

30. Hansell, R.A.; Ou, S.C.; Liou, K.N.; Roskovensky, J.K.; Tsay, S.C.; Hsu, C. Simultaneous detection/separation of mineral dust and cirrus clouds using MODIS thermal infrared window data. Geophys. Res. Lett. 2007, 34, doi:10.1029/2007GL029388.

31. Li, J.; Zhang, P.; Schmit, T.J.; Schmetz, J.; Menzel, W.P. Quantitative monitoring of a Saharan dust event with SEVIRI on Meteosat-8. Int. J. Remote Sens. 2007, 28, 2181-2186.

32. Hu, X.; Lu, N.; Zhang, P. Operational retrieval of Asian sand and dust storm from FY-2C geostationary meteorological satellite and its application to real time forecast in Asia. Atmos. Chem. Phys. 2008, 8, 1649-1659.

33. Klüser, L.; Schepanski, K. Remote sensing of mineral dust over land with MSG infrared channels: A new bitemporal mineral dust index. Remote Sens. Environ. 2009, 113, 1853-1867.

34. Tom, X.; Ackerman, S.; Guo, W. Dust and smoke detection for multi-channel imagers. Remote Sens. 2010, 2, 2347-2368.

35. Good, E.J.; Kong, X.; Embury, O.; Merchant, C.J.; Remedios, J.J. An infrared desert dust index for the along-track scanning radiometers. Remote Sens.Environ. 2012, 116, 159-176.

36. Gang, H.; Ping, Y.; Huang, H.; Ackerman, S.; Sokolik, I. Simulation of high-spectral-resolution infrared signature of overlapping cirrus clouds and mineral dust. Geophys. Res. Lett. 2006, 33, doi:10.1029/2005GL024381.

37. Pierangelo, C.; Chédin, A.; Heilliette, S.; Jacquinet-Husson, N.; Armante, R. Dust altitude and infrared optical depth from AIRS. Atmos. Chem. Phys. 2004, 4, 1813-1822.

38. Peyridieu, S.; Chédin, A.; Tanré, D.; Capelle, V.; Pierangelo, C.; Lamquin, N.; Armante, R. Saharan dust infrared optical depth and altitude retrieved from AIRS: A focus over North Atlantic - Comparison to MODIS and CALIPSO. Atmos. Chem. Phys. 2010, 10, 1953-1967.

39. DeSouza-Machado, S.G.; Strow, L.L.; Imbiriba, B.; McCann, K.; Hoff, R.M.; Hannon, S.E.; Martins, J.V.; Tanré, D.; Deuzé, J.L.; Ducos, F.; et al. Infrared retrievals of dust using AIRS: Comparisons of optical depths and heights derived for a North African dust storm to other collocated EOS A-Train and surface observations. J. Geophys. Res. 2010, 115, doi:10.1029/2009JD012842. 
40. Yao, Z.G; Li, J; Han, H.J.; Allen H.; Sohn, B.J.; Zhang P. Asian dust height and infrared optical depth retrievals over land from hyperspectral longwave infrared radiances. J. Geophys. Res. 2012, 117, doi:10.1029/2012JD017799.

41. Gangale, G.; Prata, A.J.; Clarisse, L. The infrared spectral signature of volcanic ash determined from high-spectral resolution satellite measurements. Remote Sens. Environ. 2010, 114, 414-425.

42. Barnes, W.; Pagano, T.S.; Salomonson, V.V. Prelaunch characteristics of MODIS on EOS-AM1. IEEE Trans. Geosci. Remote Sens. 1998, 36, 1088-1100.

43. Remer, L.A.; Kaufman, Y.J.; Tanré, D.; Mattoo, S.; Chu, D.A.; Martins, J.V.; Li, R.R.; Ichoku, C.; Levy, R.C.; Kleidman, R.G.; et al. The MODIS aerosol algorithm, products, and validation. J. Atmos. Sci. 2005, 62, 947-973.

44. Hess, M.; Koepke, P.; Schult, I. Optical properties of aerosols and clouds: The software package OPAC. Bull. Am. Meteorol. Soc. 1998, 79, 831-844.

45. Volz, F.E. Infrared refractive index of atmospheric aerosol substances. Appl. Optics 1972, 12, 564-568.

46. Han, H.J.; Sohn, B.J.; Huang, H.L.; Weisz, E.; Saunders, R.; Takamura, T. An improved radiance simulation for hyperspectral infrared remote sensing of Asian dust. J. Geophys. Res. 2012, 117, doi:10.1029/2012JD017466.

47. Mayer, B.; Kylling, A. Technical note: The libRadtran software package for radiative transfer calculations-Description and examples of use. Atmos. Chem. Phys. 2005, 5, 1855-1877.

48. Baum, A.; Hymsfield, J.; Yang, P.; Bedka, S. Bulk scattering properties for the remote sensing of ice clouds. Part I: Microphysical data and models. J. Appl. Meteorol. 2005, 44, 1885-1895.

49. Baum, A.; Yang, P.; Heymsfield, J.; Steven, P.; Michael, D.; Hu, Y.X.; Sarah, T. Bulk scattering properties for the remote sensing of ice clouds. Part II: Narrowband models. J. Appl. Meteorol. 2005, 44, 1897-1991.

50. Korolev, A.; Isaac, G.; Coberi, S.; Strapp, J.W.; Hallett, J. Microphysical characterization of mixed-phase clouds. Q. J. Roy. Meteorol. Soc. 2003, 129, 39-65.

51. Anderson, G.P.; Clough, S.A.; Kneizys, F.X.; Chetwynd, J.H.; Shettle, E.P. AFGL Atmospheric Constituent Profiles 0-120 km. Available online: http:/oai.dtic.mil/oai/oai?verb=getRecord\& metadataPrefix $=$ html\&identifier $=$ ADA175173 $($ accessed on 13 September 2014).

52. Wilber, A.; Kratz, D.; Cupta, S. Surface Emissivity Maps for Use in Satellite Retrievals of Longwave Radiation. Available online: http://www-cave.larc.nasa.gov/pdfs/Wilber.NASATchNote99.pdf (accessed on 13 September 2014).

(C) 2014 by the authors; licensee MDPI, Basel, Switzerland. This article is an open access article distributed under the terms and conditions of the Creative Commons Attribution license (http://creativecommons.org/licenses/by/4.0/). 